\title{
Diagnóstico histopatológico e molecular da infecção por Mycoplasma sp. em ratos mantidos em biotério convencional
}

\section{Histopathological and molecular diagnosis of Mycoplasma sp. infection in rats kept in a conventional animal facility}

\author{
Rosangela Boeck ${ }^{1}$; Ronei Saldanha Lopes ${ }^{2}$ Jane Silveira Fraga ${ }^{3}$; \\ Sandra Fernandez ${ }^{3}$; Fernando Rosado Spilki ${ }^{4 *}$
}

\section{Resumo}

\begin{abstract}
Ainfecção crônica por Mycoplasma pulmonis é freqüentemente encontrada em ratos alojados em biotérios convencionais e pode influir no resultado dos experimentos realizados com tais animais. Na forma clínica da infecção os animais desenvolvem dentre outras manifestações sinais de comprometimento do sistema respiratório. No presente estudo, relatamos o diagnóstico histopatológico e molecular da infecção por Mycoplasma sp., tanto em ratos Wistar apresentando sinais da infecção quanto em animais saudáveis mantidos na mesma colônia. A eficácia de medidas terapêuticas e profiláticas é discutida.

Palavras-chave: Mycoplasma pulmonis, ratos, diagnóstico
\end{abstract}

\begin{abstract}
The chronic infection by Mycoplasma pulmonis is frequently found in rats kept in conventional premises and may influence the results of the experiments conducted using these animals. During the clinical presentation of the infection animals develop among other manifestations clinical signs of respiratory system impairment. On the present study, we report the diagnosis the histopathological and molecular diagnosis of Mycoplasma sp. infection in Wistar rats both presenting clinical signs of infection and health animals kept in the same colony. The efficacy of therapeutic and prophylactic actions is discussed.
\end{abstract}

Key words: Mycoplasma pulmonis, rats, diagnosis

${ }^{1}$ Acadêmica do Curso de Ciências Biológicas, Universidade Feevale, Novo Hamburgo, Rio Grande do Sul, Brasil. E-mail: rosangelab@feevale.br

2 Biotério, Instituto de Ciências da Saúde, Universidade Feevale, Novo Hamburgo, Rio Grande do Sul, Brasil. E-mail: roneisl@, feevale.br

${ }^{3}$ Laboratório Biovet S.A., Vargem Grande Paulista, São Paulo, Brasil. E-mail: biovet@biovet.com.br

${ }^{4}$ Laboratório de Microbiologia Molecular, Instituto de Ciências da Saúde, Universidade Feevale, Novo Hamburgo, Rio Grande do Sul, Rodovia RS-239, n² 2755, CEP 93352-000. E-mail: fernandors@feevale.br

* Autor para correspondência 
O Mycoplasma pulmonis é o organismo que desempenha importante papel como causa de infecções respiratórias crônicas em roedores utilizados em pesquisa biomédica, atingindo tanto ratos quanto camundongos (BARRETO et al., 2002). Ainda que a infecção possa ocorrer de forma subclínica, esporadicamente a doença se manifesta na forma de pneumonia que pode ser acompanhada de sinais de labirintite e em alguns casos em prejuízos à reprodução dos animais de laboratório (CARVALHO PINTO et al., 1997; SCHOEB, 2006). Os sinais clínicos são variados e podem se desenvolver de forma separada ou em conjunto, alguns desses sinais são: i) otite média e/ou interna, induzindo à déficits no equilíbrio e rotação quando o animal é estimulado ou erguido pela cauda; ii) rinite, com espirros e manchas de sangue ao redor das narinas; iii) pneumonia com respiração difícil, debilidade progressiva e aspereza de pêlos. A doença é conhecida como Micoplasmose respiratória murina (MRM) (CARVALHO PINTO et al., 1997; BARRETO et al., 2003). Também ocorrem casos de infecção do trato genital, levando a perdas reprodutivas, especialmente em fêmeas (BROWN et al., 2001).

A principal via de transmissão é horizontal, o que facilita a disseminação deste agente para os demais ambientes do biotério, aerossóis respiratórios a curtas distâncias, contato sexual entre animais portadores, contaminação uterina e contato direto entre mãe e filhotes (CARVALHO PINTO et al., 1997; FERREIRA et al., 2008). Fatores ambientais, tais como a infecção por diferentes agentes virais, em especial o vírus Sendai, frequente em biotérios brasileiros (HOWARD; STOTT; TAYLOR, 1978; SAITO et al., 1981; SCHOEB et al., 1985; HOMBERGER; THOMANN, 1994; GILIOLI et al., 1996), condições inadequadas de manejo que incluem má higiene, má qualidade do ar, excesso de amônia, podem ser fatores desencadeantes dos sinais clínicos (SCHOEB; DAVIDSON; LINDSEY, 1982; HOMBERGER; THOMANN, 1994; GILIOLI et al., 1996). Também foi relatada detecção de Mycoplama pulmonis em bioteristas expostos ao agente pela manipulação de colônias contaminadas, mas a infecção não está associada a sinais clínicos evidentes em seres humanos (DELGADO; TIMENETSKY, 2001; FERREIRA et al., 2008).

Ainda que a infecção possa interferir nos resultados de pesquisa biomédica de diferentes áreas conduzida em animais infectados e o monitoramento da infecção por $M$. pulmonis seja amplamente recomendado, o diagnóstico da infecção é frequentemente negligenciado em nosso meio, provavelmente pela prevalência próxima de 100\% em biotérios convencionais e muitas vezes na faixa de $60 \%$ em biotérios com barreiras mais sofisticadas (GILIOLI et al., 1996; SCHOONDERMARKVAN de VEN et al., 2006). Para o diagnóstico em animais sadios infectados cronicamente ou em animais sofrendo sinais clínicos, pode-se utilizar o isolamento em meios apropriados para micoplasma que é bastante trabalhoso e passível de insucesso, ou voltar os esforços para o diagnóstico molecular, normalmente utilizando a técnica de reação em cadeia da polimerase (PCR) (SANCHEZ et al., 1994; BARRETO et al., 2003; LIANG et al., 1994). Também é utilizado para o monitoramento de rotina o teste de ELISA (enzyme linked immunosorbent assay) e outros métodos de detecção de anticorpos visando a detecção de anticorpos específicos contra M. pulmonis (DELGADO; TIMENETSKY, 2001; SCHOONDERMARK-VAN de VEN et al., 2006). Em animais que apresentam sinais clínicos evidentes, foi demonstrado que o diagnóstico histopatológico é válido em confirmar a infecção por Mycoplasma sp. como causa dos sinais clínicos observados (BARRETO et al., 2003).

Este trabalho teve como objetivo a descrição de um surto ocorrido em biotério convencional e a confirmação da etiologia através da caracterização das lesões de MRM, com ênfase às manifestações respiratórias da micoplasmose, associada ao diagnóstico molecular da infecção. No caso em questão, em um biotério localizado no Rio Grande 
do Sul, foi observada, durante a realização de experimentos variados, a presença de animais apresentando os referidos sinais de labirintite e por vezes sinais respiratórios em Rattus norvegicus, linhagem Wistar. Os experimentos foram consequentemente suspensos, com vistas a evitar a obtenção de resultados errôneos de pesquisa. Após a apresentação de tais sinais clínicos associados à presença de sinais de pneumonia hemorrágica em animais afetados ao exame de necropsia, iniciou-se a investigação $M$. pulmonis, pela suspeita clínica de MRM. Após um primeiro surto envolvendo 6 animais, outros 5 animais (em uma colônia com aproximadamente 150 ratos), foram encontrados com sinais clínicos após um período de um ano decorrido do primeiro surto. Os animais, todos machos, com idade entre três e seis meses, apresentavam sinais de doença respiratória como espirros freqüentes, secreção nasal e ocular. Foi notada ainda otite evidente com torcicolo, déficits no equilíbrio e movimento de giro quando suspensos pela cauda (por provável efeito da infecção sobre o ouvido interno). Foi observada também caquexia e pêlos arrepiados.

Para a coleta de material de trato respiratório os animais foram previamente anestesiados (associação de quetamina, $90 \mathrm{mg} / \mathrm{Kg}$ e xilazina $10 \mathrm{mg} / \mathrm{Kg}$ ) e quando atingido plano de anestesia profunda eutanasiados por exsangüinação e posterior necropsia em condições assépticas.

Para a confirmação do diagnóstico foi realizado o exame histopatológico. Fragmentos de pulmões e traquéia desses últimos 5 animais foram fixados em formol $10 \%$ tamponado, embebidos em parafina, cortados em secções de $5 \mu \mathrm{m}$ e corados com hematoxilina e eosina, conforme metodologia usual.

Foi realizada ainda a tentativa de confirmação do diagnóstico através da amplificação de fragmentos genômicos da região codificante da subunidade ribossomal 16S de Mycoplasma sp. pela técnica de PCR, conforme descrito na literatura
(OSSEWAARDE et al., 1996; VAN KUPPEVELD et al., 1992). Os mesmos 5 animais analisados em histopatologia tiveram fragmentos de tecido pulmonar analisados pela PCR. Brevemente, as amostras de pulmão foram inicialmente cortadas e maceradas em TNE modificado (Tris $10 \mathrm{mM}$; $\mathrm{NaCl}$ 0,2M; EDTA 50mM; pH8,0). O sobrenadante do macerado foi digerido com RNAse A e com proteinase K. Em seguida as amostras foram submetidas à extração de DNA com fenol, fenol/ clorofórmio, álcool isoamílico e clorofórmio/álcool isoamílico. Os ácidos nucléicos presentes na amostra foram precipitados pela adição de isopropanol e ao final, ressuspensos em Tris 10 mM pH8,0, solução que foi utilizada como molde na PCR propriamente dita. Os oligonucleotídeos iniciadores utilizados foram GPO-3 (5'-GGG AGC AAA CAG GAT TAG ATA CCC T-3') e MGSO (5'-TGC ACC ATC TGT CAC TCT GTT AAC CTC-3'), que amplificam aproximadamente $270 \mathrm{pb}$ do gene codificante de 16S do gênero Mycoplasma (OSSEWAARDE et al., 1996). As reações foram feitas com o $1 \mu \mathrm{L}$ de DNA extraído, diluído 10 ou 100x, utilizando a enzima Biolase DNA polimerase (Bioline), em seu tampão 1x concentrado, com 1,5 mM de $\mathrm{MgCl} 2,0,25 \mathrm{mM}$ de cada dNTP e 10 pmoles de cada iniciador (GPO-3 e MGSO). As misturas foram então submetidas a um ciclo de desnaturação inicial a $94^{\circ} \mathrm{C}$, seguido de 35 ciclos com $30 \mathrm{~s}$ a $94^{\circ} \mathrm{C}$ (desnaturação); $30 \mathrm{~s} \mathrm{a} 55^{\circ} \mathrm{C}$ (anelamento) e $30 \mathrm{~s} \mathrm{a} 72^{\circ} \mathrm{C}$ (extensão); tal etapa foi seguida de um ciclo de extensão final de $72{ }^{\circ} \mathrm{C}$ por 3 minutos. Os resultados foram evidenciados por eletroforese em gel de agarose $1,5 \%$ corada com brometo de etídio e visualização sob luz UV. Foram incluídos controles positivos oriundos de cultivo de Mycoplasma sp. em todas as análises, bem como controles negativos (água e reagentes).

Além dos animais apresentando sinais clínicos, foram analisados fragmentos de tecido pulmonar de outros três animais saudáveis da colônia, seguindo a metodologia descrita anteriormente. Fragmentos de pulmões de todos os animais foram ainda submetidos a tentativas de isolamento de outras 
bactérias patogênicas do trato respiratório superior, sendo os resultados negativos.

As lesões macroscópicas observadas nos pulmões dos animais com patologia aparente, caracterizavamse com consistência firme e cor cinza-escura, áreas em depressão de cor acinzentada e nódulos amarelos de diferentes tamanhos, com aspecto purulento ao corte. Para o restante dos animais, sem sinais clínicos, os pulmões não apresentavam alterações macroscópicas ou microscópicas. Como lesões microscópicas mais frequentes nos animais analisados, observou-se infiltração mononuclear moderada a grave do parênquima pulmonar, infiltrado linfocitário perivascular e peribronquiolar consistentes com a infecção por M. pulmonis, a qual foi confirmada pela detecção molecular de fragmentos específicos do genoma do gênero Mycoplasma. Ainda que os animais saudáveis não apresentassem lesões histopatológicas, um dos animais sem sinais clínicos também foi positivo à PCR, evidenciando o caráter subclínico frequente da infecção (Figura 1).

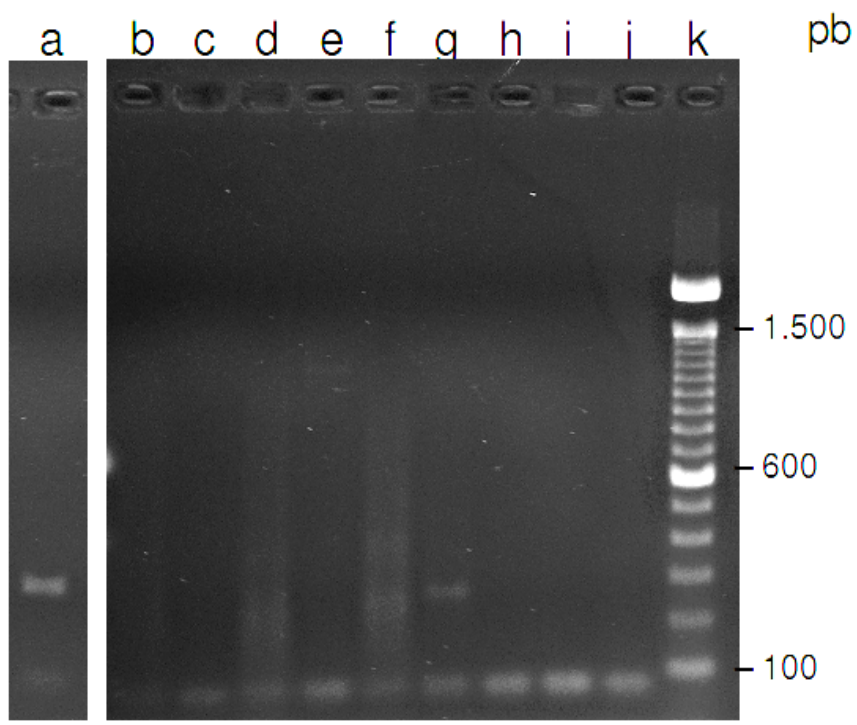

Figura 1. Resultados de reação em cadeia da polimerase para amplificação de fragmento genômico correspondente à região codificante da subunidade ribossomal $16 \mathrm{~S}$ de Mycoplasma $\mathrm{sp}$. em pulmões de ratos Wistar saudáveis, sendo o pulmão n 3 positivo (linha g). a) Controle positivo; b) Pulmão 1 - amostra de DNA diluída 10x; c) Pulmão 1 100x; d) Pulmão 2 - 10x; e) Pulmão 2 - 100x; f) Pulmão 3 - 10x; g) Pulmão 3 - 100x; h) Controle negativo - DNA; i) Controle negativo $-\mathrm{H}_{2} \mathrm{O}$; j) Controle negativo - Reagente; k) marcador de peso molecular $100 \mathrm{pb}$. Gel de agarose $1,5 \%$ corado com brometo de etídio observado em luz UV.

Após a confirmação do diagnóstico, visando evitar o aparecimento de novos casos com sinais clínicos evidentes, foram tomadas medidas de controle que envolveram principalmente o reforço da biossegurança e melhoria da ambiência, especialmente no que tange ao controle da ventilação e sacrifício de animais com idade superior a seis meses na colônia bem como de animais em contato com animais doentes. Conforme mencionado anteriormente, vários fatores ambientais e co- infecções com outros patógenos contribuem para a maior disseminação e aparecimento de sinais clínicos em colônias infectadas (SAITO et al., 1981; SCHOEB; DAVIDSON; LINDSEY, 1982; HOMBERGER; THOMANN, 1994). Tais medidas tem se mostrado efetivas em evitar sinais clínicos, tendo em vista que no ano seguinte aos últimos casos relatados, houve apenas um animal manifestando sinais da MRM. Uma tentativa piloto utilizando oxitetraciclina diluída na água de beber, 
na dose de $10 \mathrm{mg} / \mathrm{Kg}$, durante 14 dias também foi realizada em um grupo de 10 animais neste período; não foram observados sinais clínicos da infecção neste grupo, mas o exame com PCR evidenciou que alguns dos animais continuavam infectados com Mycoplasma sp., o que reforça o caráter enzoótico da infecção e a dificuldade na sua erradicação (SCHOONDERMARK-VAN de VEN et al., 2006).

Os sinais clínicos aqui observados, associados aos achados histopatológicos, são fortemente indicativos da infecção por M. pulmonis. Já foi relatado no passado que a histopatologia é um diagnóstico apropriado para esta infecção (BARRETO et al., 2003). A técnica de PCR utilizada neste estudo indica a presença do gênero Mycoplasma spp.. Análises complementares para determinação da espécie, tais como PCRs diferenciais ou sequenciamento nucleotídico podem ser realizados quando não houverem sinais clínicos evidentes ou achados histopatólógicos, especialmente em infecções subclínicas e em programas de erradicação da infecção em colônias.

\section{Agradecimentos}

FRS é Bolsista de Produtividade do CNPq.

\section{Referências}

BARRETO, M. L.; NASCIMENTO, E. R.; CAMPOS, C. A. M.; NASCIMENTO, M. G. F.; LIGNON, G. B.; LIRA, M. L. F.; SILVA, R .G. Detection of Mycoplasma pulmonis in laboratory rats. Brazilian Journal of Microbiology, São Paulo, v. 33, n. 3, p. 260-264, 2002. Disponível em: <http://www.scielo.br/cgi-bin/fbpe/ fbtext?pid=S1517-83822002000300015>. Acesso em:19 abr. 2009.

BARRETO, M. L.; NASCIMENTO, E. R.; PRESGRAVE, R.; MARTINO, C. A. Diagnóstico patológico da micoplasmose respiratória murina em Rattus norvegicus. Acta Scientiae Veterinariae, Porto Alegre, v. 31, n. 2, p. 81-87, 2003. Disponível em: <http://www.ufrgs.br/favet/ revista/31-2/artigo556.pdf > . Acesso em: 03 maio 2009.
BROWN, M.; PELTIER, M.; HILLIER, M.; CRENSHAW, B.; REYES, L. Genital mycoplasmosis in rats: a model for intrauterine infection. American Journal Reproductive Immunology, Vernon Hills, v. 46, n. 3, p. 232-241, 2001. Disponível em: <http:// www3.interscience.wiley.com/journal/120706213/ abstract?CRETRY $=1 \&$ SRETRY $=0>$. Acesso em: 08 maio 2009.

CARVALHO PINTO, C.; GREMIAO, C. D.; MOCHIARO, P. C.; GILIOLI, R.; CARVALHO, E. Q. Control sanitario en animales de laboratorio: un enfoque en infección pulmonar. Animales de Experimentación, San Jose, v. 3, n. 1, p. 26-29, 1997.

DELGADO, M. O.; TIMENETSKY, J. Immunoblot profiles of sera from laboratory rats naturally infected with Mycoplasma pulmonis and technicians exposed to infected animal facilities. Brazilian Journal of Microbiology, São Paulo, v. 32, n. 4, p. 301-304, 2001. Disponível em: <http://www.scielo.br/scielo. php? pid $=$ S $1517-83822001000400009 \&$ script $=$ sci_ arttext\&tlng=en>. Acesso em: 07 maio 2009.

FERREIRA, J. B.; YAMAGUTI, M.; MARQUES, L. M.; OLIVEIRA, R. C.; NETO, R. L.; BUZINHANI, M.; TIMENETSKY, J. Detection of Mycoplasma pulmonis in laboratory rats and technicians. Zoonoses and Public Health, Washington, v. 55, n. 5, p. 229-234, 2008. Disponível em: <http:/www3.interscience.wiley. com/ journal/119423750/abstract>. Acesso em: 23 mar. 2009.

GILIOLI, R.; SAKURADA, J. K.; ANDRADE, L. A. G.; KRAFT, V.; MEYER, B.; RANGEL, H. A. Virus infection in rat and mouse colonies reared in Brazilian animal facilities. Laboratory Animal Science, Memphis, v. 46, n. 5, p. 582-584, 1996. Disponível em: <http:// www.ncbi.nlm.nih.gov/pubmed/8905597>. Acesso em: 08 maio 2009.

HOMBERGER, F. R.; THOMANN, P. E. Transmission of murine viruses and mycoplasma in laboratory mouse colonies with respect to housing conditions. Laboratory Animals, London, v. 28, n. 2, p. 113-120, 1994. Disponível em: <http://la.rsmjournals.com/cgi/content/ abstract/28/2/113>. Acesso em: 15 abr. 2009.

HOWARD, C. J.; STOTT, E. J.; TAYLOR, G. The effect of pneumonia induced in mice with Mycoplasma pulmonis on resistance to subsequent bacterial infection and the effect of a respiratory infection with Sendai virus on the resistance of mice to Mycoplasma pulmonis. Journal of General Microbiology, London, v. 109, n. 1, p. 79-87, 1978. Disponível em: <http://www.ncbi.nlm.nih. gov/pubmed/215702>. Acesso em: 01 maio 2009. 
LIANG, C. T.; WU, S. C.; HUANG, Y. T.; LIN, Y. C.; CHANG, W. J.; CHOU, J. Y.; LIANG, S. C.; LIU, C. $\mathrm{H}$. Immunohistochemical diagnosis of mouse hepatitis virus and Mycoplasma pulmonis infection with murine antiserum. Journal of Comparative Pathology, Bristol, v. 131, n. 2/3, p. 214-220, 1994. Disponível em: <http:// dx.doi.org/10.1016/j.jppa.2004.04.003>. Acesso em: 02 maio 2009.

OSSEWAARDE, J. M.; DE VRIES, A.; BESTEBROER, T.; ÂNGULO, F. Application of a Mycoplasma groupspecific PCR for monitoring decontamination of Mycoplasma-infected Chlamydia sp. strains. Applied and Environmental Microbiology, Washington, v. 62, n. 2, p. 328-331. Disponível em: <http://aem.asm.org/cgi/ reprint/62/2/328.pdf>. Acesso em: 08 maio 2009.

SAITO, M.; NAKAGAWA, M.; SUZUKI, E.; KINOSHITA, K.; IMAIZUMI, K. Synergistic effect of Sendai virus on Mycoplasma pulmonis infection in mice. Japanese Journal of Veterinary Science, Tokio, v. 43, n. 1, p. 43-50, 1981. Disponível em: <http://rms1.agsearch. agropedia.affrc.go.jp/contents/JASI/pdf/society/223880.pdf $>$. Acesso em: 01 maio 2009.

SANCHEZ, S.; TYLER, K.; ROZENGURT, N.; LIDA, J. Comparison of a PCR-based diagnostic assay for Mycoplasma pulmonis with traditional detection techniques. Laboratory Animals, London, v. 28, n. 3, p. 249-256, 1994. Disponível em: <http://la.rsmjournals. com/cgi/content/abstract/28/3/249>. Acesso em: 08 maio 2009.

SCHOEB, T. R.; KERVIN, K. C.; LINDSEY, J. R. Exacerbation of murine respiratory mycoplasmosis in gnotobiotic $\mathrm{F} 344 / \mathrm{N}$ rats by Sendai virus infection. Veterinary Pathology, Madison, v. 22, n. 5, p. 272-282, 1985. Disponível em: <http://www.vetpathology.org/cgi/ content/abstract/22/3/272>. Acesso em: 02 abr. 2009.
SCHOEB, T. R. Mycoplasma pulmonis, other murine mycoplasmas, and cilia-associated respiratory bacillus. In: FOX, J. G.; BARTHOLD, S.; DAVISSOM, M.; NEWCOMER, C.; QUIMBY, F. W.; SMITH, A. (Ed.). The mouse in biomedical research. Diseases. New York: Academic Press, 2006, v. 2, p. 437-468.

SCHOEB, T. R.; DAVIDSON, M. K.; LINDSEY, J. R. Intracage ammonia promotes growth of Mycoplasma pulmonis in the respiratory tract of rats. Infection and Immunity, Washington, v. 38, n. 1, p. 212-217, 1982. Disponível em: <http://www.pubmedcentral.nih.gov/ articlerender.fcgi? artid $=347721>$. Acesso em: 03 maio 2009.

SCHOONDERMARK-VAN DE VEN, E. M. E.; PHILIPSE-BERGMANN, I. M. A.; VAN DER LOGT, J. T. M. Prevalence of naturally occurring viral infections, Mycoplasma pulmonis and Clostridium piliforme in laboratory rodents in Western Europe screened from 2000 to 2003. Laboratory Animals, London, v. 40, n. 2, p. 137-143, 2006. Disponível em: <http://la.rsmjournals. com/cgi/content/abstract/40/2/137>. Acesso em: 05 maio 2009.

VAN KUPPEVELD, F. J.; VAN DER LOGT, J. T. M.; ANGULO, A. F.; VAN ZOEST, M. J.; QUINT, W. G.; NIESTERS, H. G.; GALAMA, J. M.; MELCHERS, W. J. Genus-and species-specific identification of mycoplasmas by $16 \mathrm{~S}$ rRNA amplification. Applied and Environmental Microbiology, Washington, v. 58, n. 8, p. 2606-2615, 1992. Disponível em:<http://www.pubmedcentral.nih. gov/articlerender.fcgi?artid=195828>. Acesso em: 08 maio 2009. 